University of Nebraska - Lincoln

DigitalCommons@University of Nebraska - Lincoln

\title{
Interventions for families victimized by child sexual abuse: Clinical issues and approaches for child advocacy center-based services
}

\author{
Poonam Tavkar \\ University of Nebraska-Lincoln, ptavkar@msn.com \\ David J. Hansen \\ University of Nebraska-Lincoln, dhansen1@unl.edu
}

Follow this and additional works at: https://digitalcommons.unl.edu/psychfacpub

Part of the Psychiatry and Psychology Commons

Tavkar, Poonam and Hansen, David J., "Interventions for families victimized by child sexual abuse: Clinical issues and approaches for child advocacy center-based services" (2011). Faculty Publications, Department of Psychology. 543.

https://digitalcommons.unl.edu/psychfacpub/543

This Article is brought to you for free and open access by the Psychology, Department of at DigitalCommons@University of Nebraska - Lincoln. It has been accepted for inclusion in Faculty Publications, Department of Psychology by an authorized administrator of DigitalCommons@University of Nebraska - Lincoln. 


\title{
Interventions for families victimized by child sexual abuse: Clinical issues and approaches for child advocacy center-based services
}

\author{
Poonam Tavkar and David J. Hansen
}

\begin{abstract}
Department of Psychology, University of Nebraska-Lincoln, 238 Burnett Hall, Lincoln, NE 68588-0308, USA
Corresponding author - P. Tavkar, tel 402 472-2351, fax 402 472-6804, email ptavkar@msn.com
\end{abstract}

\begin{abstract}
Child sexual abuse poses serious mental health risks, not only to child victims but also to non-offending family members. As the impact of child sexual abuse is heterogeneous, varied mental health interventions should be available in order to ensure that effective and individualized treatments are implemented. Treatment modalities for child victims and non-offending family members are identified and described. The benefits of providing on-site mental health services at Child Advocacy Centers to better triage and provide care are discussed through a description of an existing Child Advocacy Center-based treatment program. Recommendations for research and clinical practice are provided.
\end{abstract}

Keywords: child sexual abuse, interventions, child advocacy centers, families

\section{Contents}

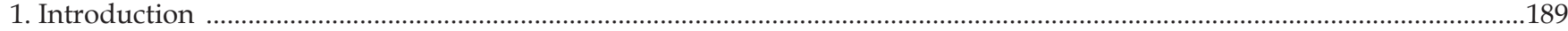

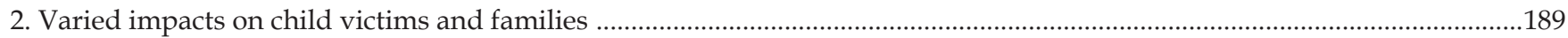

3. Mental health interventions for child victims and non-offending family members ...........................................................190

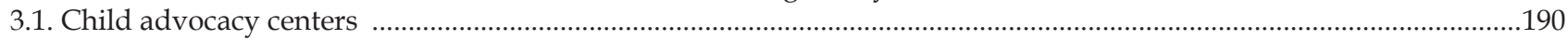

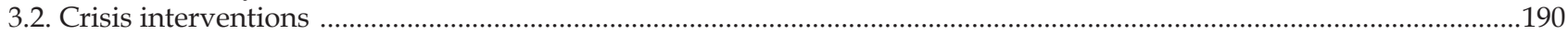

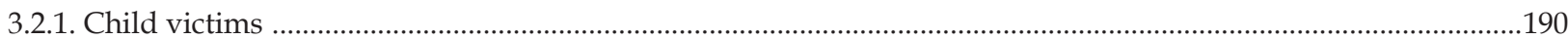

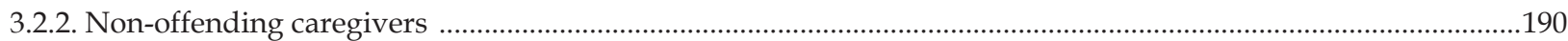

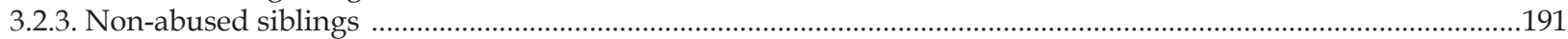

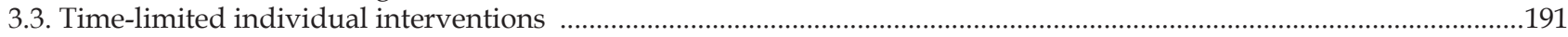

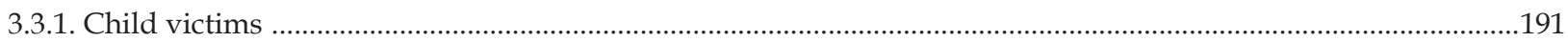

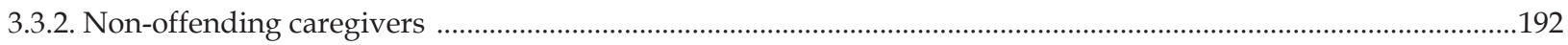

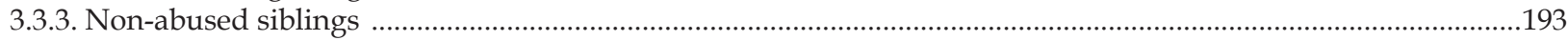

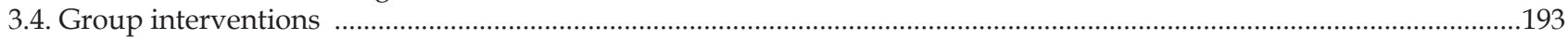

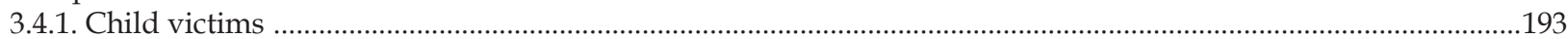

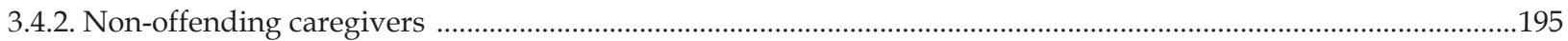

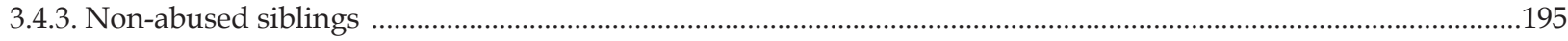

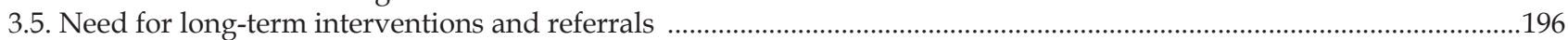

4. A model for mental health services in child advocacy centers ............................................................................................196

4.1. Project SAFE: Group treatment for sexually abused youth and their non-offending caregivers ..................................196

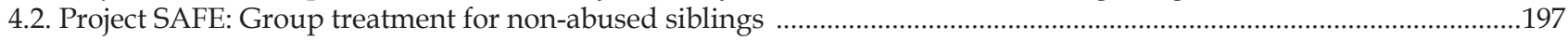

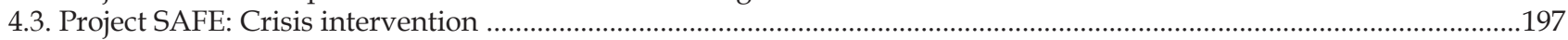

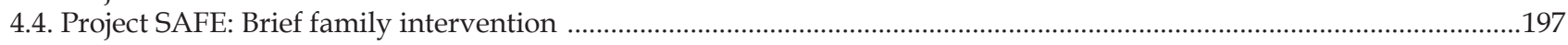

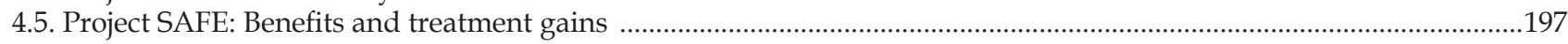

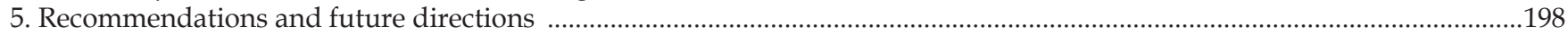

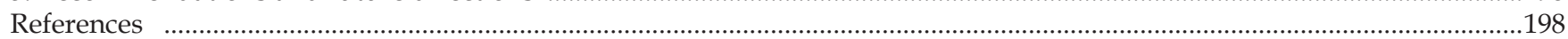




\section{Introduction}

Child sexual abuse (CSA) has received increasing attention and concern in today's society as it continues to pose serious and pervasive mental health risks to child victims and their non-offending family members. There is increasing documentation that child and adolescent victims of sexual abuse and their non-offending parents and siblings are in need of mental health services (e.g., Baker, Tanis, \& Rice, 2001; Heflin, Deblinger, \& Fisher, 2000; Putnam, 2003; Swenson \& Hanson, 1998). In the aftermath of CSA, families often face multiple challenges (e.g., loss of income, loss of a caregiver, change of residence, and limited community support) that are often accompanied by psychological distress, such as depression, guilt, embarrassment, grief symptomatology, and secondary trauma (e.g., Deblinger, Hathaway, Lippman, \& Steer, 1993; Manion et al., 1996; Regehr, 1990). Given these difficulties, the need for accessible and varied interventions is paramount for not only CSA victims, but also for their non-offending family members.

Child Advocacy Centers (CACs) are increasingly being utilized as initial access sites for mental health services for sexual abuse victims, either through the provision of referrals to community agencies, or on-site care. As community-based programs designed to be child-friendly facilities, CACs approach child maltreatment as a multifaceted community problem (Jackson, 2004). Since the establishment of the first CAC in Huntsville, Alabama in 1985, there are more than 900 established and developing CACs nationwide as of 2007 (National Children's Advocacy Center, 2007). Child Advocacy Centers may be the optimal locations for immediate on-site services within a convenient, accessible, and familiar environment, as well as for prompt provision of referrals.

Given the continued prevalence of CSA in today's society and increasing utilization of CACs as the initial sites accessed by families following disclosure, the purposes of the present paper are twofold. First, various types of mental health interventions and modalities available to child victims and their families as they begin to deal with the consequences of CSA are described. The modalities of interventions that are examined include: (a) crisis interventions in the immediate aftermath of disclosure and investigation, (b) brief time-limited individual interventions, (c) group interventions, and (d) the need for longer-term interventions and referrals. The modalities of interventions, as organized in this paper, focus on attending to needs of families as they present at CACs following CSA. That is, while some families may experience marked distress in the immediate aftermath of disclosure and require prompt crisis or brief time-limited interventions, others may benefit from group interventions or referrals for longer-term services. For this reason, a variety of interventions will be discussed. Relevant literature is reviewed and a model mental health program implemented at a local CAC is described.

Second, rationale and recommendations for the dissemination of these interventions on-site at CACs will be provided. While a review of interventions currently provided at CACs is warranted, no literature presently exists. Recommendations for future directions for research and clinical practice are provided. Prior to examining treatment approaches, the heterogeneous impacts of CSA on child victims and non-offending family members will be explored to provide an understanding of the types of services needed. For the remainder of this paper, "victims" include children and adolescents, and "non-offending caregivers" include biological parents as well as any primary caregiver (i.e., step or foster parent), unless explicitly noted.

\section{Varied impacts on child victims and families}

In contrast to youth in general who may be referred to mental health services in response to a psychological disturbance, behavioral problems, or emotional distress, victims of CSA are initially brought to the attention of professionals because of the trauma they have endured. Thus, it is understandable that the impact of CSA on the child victim is identified as quite complex and heterogeneous, and is commonly described as short-term and/or long-term in its effects. While much research and clinical practice has focused on the varied impacts and difficulties experienced by child victims (e.g., Beitchman, Zucker, Hood, daCosta, \& Akman, 1991; Beitchman et al., 1992; Finkelhor, 1990; Swanston et al., 2003; Wolfe, 2006), non-offending caregivers have been largely overlooked. In a review of past literature, Corcoran (1998) noted that non-offending mothers had generally been viewed negatively by others, specifically as being indifferent, passive, and permissive of the sexual abuse. In addition, Deblinger et al. (1993) and Heflin et al. (2000) noted that the literature on CSA has been highly critical of non-offending mothers of incest cases, and tended to view these mothers as indirectly responsible for the abuse, denying the abuse, colluding with the perpetrator, encouraging their daughters to assume a parental/spousal role, and being socially isolated.

However, few empirical studies support these negative views of non-offending caregivers. Rather, the majority of nonoffending caregivers appear to suffer greatly or be traumatized upon discovery of their children's sexual abuse (Corcoran, 1998; Deblinger et al., 1993; Manion et al., 1996; Newberger, Gremy, Waternaux, \& Newberger, 1993). Initial reactions by non-offending caregivers may include anger toward the perpetrator, displaced anger toward family members, guilt, self-blame, helplessness, panic, denial, shock, embarrassment, feelings of betrayal, a desire for secrecy, and fear for the child victim(e.g., Elliott \& Carnes, 2001; Manion et al., 1996). In a longitudinal study of maternal adjustment, Newberger et al. (1993) found that non-offending mothers exhibited a range of symptoms, including: depression, anxiety, hostility, somatic symptoms, paranoid ideation, and psychoticism. In addition, non-offending caregivers may attempt suicide or require hospitalization following their child's disclosure (Deblinger et al., 1993), and often display symptoms of PTSD and grief symptomatology (Manion et al., 1996). Stauffer and Deblinger (1996) noted that non-offending parents often experienced elevated levels of psychosocial distress up to an average of two years following their child's disclosure of CSA.

While the literature on paternal functioning following the disclosure of extrafamilial CSA has been limited, Manion et al. (1996) reported that fathers are just as likely to experience significant levels of distress as non-offending mothers.

Non-offending caregivers may also experience considerable social, emotional, and economic consequences (e.g., stigma, increased feelings of isolation, loss of partner, loss of income, disruption of the family especially with intrafamilial CSA, change of residence, and dependence on government assistance; Elliott \& Carnes, 2001), which may be more pronounced depending on whether the abuse is intrafamilial or extrafamilial. However, Manion et al. (1996) found that the majority of families in their study were able to cope fairly well despite the disclosure of extrafamilial CSA. Thus, the impact on non-offending caregivers appears to be variable, as is shown for child victims of CSA. Given the critical need for support from non-offending caregivers, particularly following disclosure, and the impact of parental distress on the child's recovery, the impact of CSA on nonoffending caregivers warrants further attention (e.g., Corcoran, 1998; Stauffer \& Deblinger, 1996).

Similarly, the literature on the short- and long-term effects on non-abused siblings of child victims is unfortunately sparse (Hill, 2003). Not surprisingly, siblings are not immune to the many changes that commonly take place following disclosure of CSA. Siblings may face several adverse effects, including: psychological distress of having viewed or known of the abuse; greater risk of victimization; change in family dynamics; change of residence; change of school districts; loss of friends; increased feelings of isolation, shame, and stigma; and reduced family income (e.g., Baker et al., 2001; Swenson \& Hanson, 1998). The level of parental and peer support for the non-abused sibling, as well as their own psychological functioning following disclosure of CSA by the victim, may warrant the need for psychologi- 
cal services. Additionally, as parental support of the child victim has been shown to be of great importance to the child's functioning, so too is the support of siblings (Baker et al., 2001).

The heterogeneous presentations and negative consequences of CSA for the sexually abused child, non-offending caregivers, and non-abused siblings necessitates the need for comprehensive mental health services that are better suited to address these varied concerns. Regarding the implementation and dissemination of mental health services, the following factors should continue to be examined more rigorously: the format of services (individual vs. group), onset of services (crisis/immediate vs. delayed onset), duration (single session vs. time-limited vs. longer-term services), location (inpatient vs. outpatient), and topics included (e.g., prevention skills, coping skills, psychoeducation, and parenting skills).

\section{Mental health interventions for child victims and non-of- fending family members}

\subsection{Child advocacy centers}

Routinely, child victims of maltreatment and their families have been directed through multiple agencies in order to gather evidence of abuse and initiate the legal process in successfully prosecuting the alleged perpetrators. However, this approach has been criticized for its apparent shortcomings, among those for inducing anxiety in the child victim, non-offending parent(s), and non-abused sibling(s), due to needing to report the abuse to multiple individuals in numerous settings, difficulties in transportation to multiple locations (e.g., medical examinations, court), and overall lack of coordination across these agencies (e.g., Jackson, 2004; Smith, Witte, \& Fricker-Elhai, 2006). As a result, many communities have established CACs to address these shortcomings.

Child Advocacy Centers are increasingly utilized as initial sites for access to therapy, whether on-site and/or through prompt referrals to community agencies. As mental health services are believed to "reduce the emotional impact of disclosure, to mediate the long-term effects of abuse and disclosure, and to reduce or eliminate the risk of future victimization" (Jackson, 2004, p. 417), the CAC model advocates a clear need for mental health services, not only for the child victim, but also for nonoffending family members who are also entangled in the aftermath of CSA. While the majority of National Children's Alliance (NCA)-accredited CACs provide mental health services to children and non-offending parents, only about $51 \%$ provide these services on-site (Jackson, 2004). Further, little is known about the types of interventions implemented across CACs, as well as the availability of services or referrals provided to non-abused siblings.

The following sections describe the varied mental health interventions currently available to child victims of CSA, non-offending caregivers, and non-abused siblings, and provide recommendations for establishing these services at CACs. Project SAFE (Sexual Abuse Family Education), a mental health treatment program conducted onsite at a local CAC will be described as an example program that offers a variety of interventions. Given that the purpose of this paper is to review child-focused interventions and the goal of the CAC model is to provide support and advocacy for the child victim and non-offending family members, interventions for offenders and family preservation models are not included. Also, interventions examined in this review are not meant to be exhaustive but chosen based on support demonstrated in the literature.

\subsection{Crisis interventions}

\subsubsection{Child victims}

The disclosure of CSA and its immediate associated consequences frequently creates a period of crisis for the child and family, particularly in cases of intrafamilial CSA (e.g., removal of offender, disruption of family composition). During this time, the child and family may be more amenable to external sources of support, providing mental health professionals with a unique opportunity to intervene at a critical period (Heflin et al., 2000). The process of disclosure may be anxiety-provoking for many given the subsequent involvement with the legal system, forensic interviews, medical examinations, and/or mental health evaluations, as well as potential changes within the family. Child victims may also necessitate help handling their immediate feelings about the sexual abuse, as well as their emotional development (Schetky, 1988). Given the heterogeneity of presenting symptoms of child victims of CSA immediate treatment needs may vary considerably.

Lanktree (1994) noted that the initial stage following disclosure should entail a psychological evaluation, in order to gather background information, assess the presenting problem, obtain a family history, and gather information about the sexual abuse, as well as other forms of maltreatment, from which an individualized treatment plan may then be formulated. The initial interviews with the child victim should utilize standardized assessment measures, in order to gather information on symptomatology, cognitions, attributions, and level of social support (Hecht, Chaffin, Bonner, Worley, \& Lawson, 2002). Cohen, Berliner, and Mannarino (2000) noted the use of psychological debriefing as a "psychological first aid" (p. 33) in screening children for significant psychological symptoms and providing appropriate referrals for more intensive treatments for maltreatment. These two to three sessions, which are modified criticalincident debriefings for children, are focused on helping to clarify the facts about the traumatic event, normalize responses to the trauma, encourage expression of feelings, and use simple problem-solving skills. In an evaluation of psychological services, Grosz, Kempe, and Kelly (1999) provided child victims with evaluations and subsequent crisis counseling sessions that focused on helping victims share information with their non-offending parents about their trauma and facilitate disclosure.

Given the limited availability of crisis interventions for child victims, as well as limited details of what these counseling sessions entail, the need for accessible and early intervention services, as well as standardized treatments to promote generalizability for child victims remain. In addition, the provision of referrals for additional psychological services may be needed. While documented crisis interventions for child victims are scant, immediate interventions for non-offending caregivers are more prevalent, which may serve to facilitate the child victim's postabuse recovery. As noted by Grosz et al. (1999), approximately $24 \%$ of their sample of CSA victims did not demonstrate the need for additional services after the evaluation and crisis counseling, particularly for those who had a supportive parent, had experienced minor abuse, and exhibited few behavior problems.

\subsubsection{Non-offending caregivers}

Across child victims, non-offending caregivers appear to play a crucial role in influencing their child's post-abuse adjustment and recovery. That is, assisting caregivers in overcoming psychosocial difficulties that may impede their ability to be supportive and therapeutic to their children may help to strengthen the child's greatest potential "natural resource" (Heflin et al., 2000, p.170) and thereby optimize the child's immediate and long-term adjustment (e.g., Corcoran, 2004; Deblinger, Stauffer, \& Steer, 2001; Deblinger et al., 1993).

In a sample of non-offending mothers studied by deYoung (1994), 60\% provided some level of support or protection to their child within the first hour following disclosure. However, many studies have noted the impact of a non-offending caregiver's own immediate and long-term psychological distress on potentially diminishing their support toward their child (e.g., Regehr, 1990; Tourigny, Hébert, Daigneault, \& Simoneau, 2005). Elliott and Carnes (2001) proposed that inadequate support by non-offending parents may be due to several factors, including an initial lack of help during the initial crisis of disclosure and 
difficulty accessing services. Given these immediate stressors related to disclosure, as well as the varied parental responses to abuse allegations, the need to immediately address these concerns and involve non-offending caregivers in treatment appears to be vital.

To deal with concerns of secondary traumatization as well as other psychosocial difficulties, non-offending caregivers should be immediately evaluated and offered appropriate treatment in order to provide support and guidance (Deblinger et al., 1993; Newberger et al., 1993). Grosz et al. (1999) offered crisis counseling to child victims and non-offending caregivers, evaluations through individual and family sessions, and victims were helped to share disclosure information with their parents. Jinich and Litrownik (1999) showed non-offending parents of schoolaged CSA victims, during the crisis phase of disclosure, either a 20-minute videotape based on social learning theory and teaching parents about conveying appropriate support to their children, or a control videotape of comparable length. Parents who had viewed the social learning videotape were rated as more supportive by observers, and their children reported significantly less distress on parental unsupportive behaviors than those exposed to the control videotape. While this study highlighted the need for immediately addressing and conveying the importance of parental support for the child victim, it was not clear whether raters and children were unaware of the videotape conditions to which each parent had been exposed.

Although there are a wide range of interventions offered to non-offending caregivers, few rigorous studies have been completed (Elliott \& Carnes, 2001). While studies on crisis interventions for non-offending caregivers are limited according to a review of the literature, several areas of intervention have been examined. As non-offending parents often experience multiple emotions about their child (e.g., guilt, protectiveness), feelings toward the offender (e.g., desire for retribution, guilt about the impact on the offender's family), feelings about themselves (e.g., guilt, self-blame, doubting their parenting abilities), and feelings toward the system (e.g., fear about the impact on the child), Regehr (1990) suggested that they require the opportunity to vent their conflicting feelings in therapy sessions that do not include their child.

Elliott and Carnes (2001) proposed that the goal should be to help parents remain calm, continue to focus on their child's needs, and objectively examine the emerging evidence of the abuse. Additionally, the goal should be to quickly and effectively improve the parent's ability to offer consistent and strong support and protection, and provide the parents with considerable education and their own support (Elliott \& Carnes, 2001). Overall, Corcoran (2004) proposed the need to implement and empirically evaluate more interventions during the disclosure phase, especially given the importance of parental supportiveness at this critical time.

\subsubsection{Non-abused siblings}

While siblings share physical and emotional resources, critical parental attention, and parental support, little research has been conducted on the short- and long-term effects of CSA on the child victim's siblings. Intrafamilial CSA may include additional difficulties for family members, such as blurred boundaries and greater isolation from their communities. However, siblings of victims of extrafamilial CSA may also experience significant distress (e.g., feelings of isolation and stigma, confusion due to lack of information, distress due to involvement in the investigation, limited attention from parents and professionals who need to be attentive to the child victim; Baker et al., 2001; Grosz et al., 1999). As noted for child victims and non-offending caregivers, crisis interventions for non-abused siblings are also markedly limited. Along with family and individual interviews, Grosz et al. (1999) provided individual crisis counseling, family sessions, recommendations, and treatment plans for siblings. Immediate evaluations of psychological distress experienced by siblings, not only for their own immediate and long-term adjust- ment, but also to address the potential impact on the child victim due to limited family support, appear to be important.

\subsection{Time-limited individual interventions}

Following evaluations of psychosocial functioning and crisis counseling sessions, many may require additional therapeutic services. As noted by Saywitz, Mannarino, Berliner, and Cohen (2000), the onset of services should not be delayed for too long given the risks of exacerbating symptoms, or symptoms becoming chronic and resistant to treatment. Additionally, given the current limitations on being able to reliably predict how an individual will react following CSA, or secondary trauma, the need to have prompt and varied interventions available is critical. The following section will discuss time-limited individual interventions for victims of CSA and non-offending family members, particularly in cases when group treatments are not appropriate (e.g., safety issues, severe psychopathology) or prior to family therapy sessions for cases of intrafamilial CSA. Further, support for time-limited individual interventions initiated before group therapy includes the need for many to explore more upsetting material through a one-on-one trusting relationship with a therapist, as well as more attention some may need that a group environment cannot provide (Lanktree, 1994).

\subsubsection{Child victims}

According to Saywitz et al. (2000), studies in general have identified four sizeable groups of child victims of CSA that have been considered for treatment: asymptomatic; those with few symptoms, but below clinical significance; serious psychiatric symptoms such as isolated PTSD, depression, aggression, and sexual behavior problems; and those meeting full criteria for psychiatric disorders. Given such varied impacts, individual time-limited interventions may provide the opportunity to focus on specific psychological difficulties such as trauma-related symptoms, and cognitive distortions.

Based on the Office for Victims of Crime (OVC) guidelines for empirically supported treatments for child physical and sexual abuse (Saunders, Berliner, \& Hanson, 2004), only one treatment, Trauma-Focused Cognitive Behavioral Therapy (TF-CBT; Chaffin \& Friedrich, 2004; Cohen, Deblinger, \& Mannarino, 2005) was found to be well supported and efficacious. Based on learning and cognitive theories, TF-CBT was originally developed to treat adult survivors of trauma as it has proven to be effective in treatment for PTSD symptoms. TF-CBT was modified for children and adolescents to reduce negative emotional and behavioral responses and correct maladaptive attributions and beliefs related to the traumatic experiences. TF-CBT also provides support and skills to non-offending parents to effectively respond to their children and cope with their own emotional distress (Cohen \& Deblinger, 2004).

Typically conducted over 12 to 16 sessions, TF-CBT encompasses several treatment components. Psychoeducation is provided on topics that include child abuse, sexual behaviors, typical reactions to abuse, and safety skills. Gradual exposure techniques to address the abusive events are taught through talking, writing, drawing, and/or symbolic recounting (e.g., puppets, play objects). Stress management techniques are learned, which include thought stopping, muscle relaxation, and breathing exercises. In order to correct inaccurate attributions about the abusive experience, cognitive reframing is utilized. The parent components of TF-CBT consist of parallel or conjoint sessions that include psychoeducation, anxiety management skills, thought stopping, and gradual exposure. Parents are also taught behavior management skills to deal with disruptive child behaviors. Finally, to enhance communication and create opportunities for therapeutic change regarding the abuse, working with the family is also emphasized (Berliner \& Elliott, 2002; Cohen \& Deblinger, 2004).

Many studies have been conducted that demonstrate the efficacy of TF-CBT for CSA victims and superior outcomes over 
other treatments. In a study by Cohen and Mannarino (1996), 69 children ages 3 to 7 years were randomly assigned to either 12 sessions of TF-CBT with a parent component or 12 sessions of nondirective supportive therapy (NST). Those in the TF-CBT condition demonstrated significant improvements in PTSD symptoms, as well as internalizing and externalizing behaviors. These gains were maintained at a 12-month follow-up. In a study examining the effectiveness of treatment for 43 sexually abused preschoolers and their primary caregivers, Cohen and Mannarino (1997) compared 12 sessions of individualized CBT for Sexually Abused Preschoolers (CBT-SAP) with 12 individual sessions of NST. The NST condition focused on reducing hopelessness and anxiety, increasing support by caregivers, providing empathy, and validating feelings. The CBT-SAP was shown to have symptomatic improvements compared to NST, with significant reductions in sexual behavior problems (Cohen \& Mannarino, 1997).

Deblinger, Lippman, and Steer (1996) also conducted a study randomly assigning 100 children to four different conditions: TFCBT for children only, TF-CBT for parent only, TF-CBT for child and parent, or treatment as usual (TAU; weekly, intermittent, or no treatment). The TF-CBT child components were shown to result in decreases of PTSD symptoms over the TAU. The TF-CBT parent components were shown to reduce depressive symptoms and externalizing behaviors for the child victims, and increase parenting skills, over the TAU. These gains were maintained at a two-year follow-up. Further, King et al. (2000) study compared 20 sessions of TF-CBT, 20 sessions of TF-CBT without a family treatment component, and a wait-list condition for 36 victims of CSA, ages 5-17 years who were randomly assigned to one of the three conditions. Those in the TF-CBT condition demonstrated greater improvements in depression, fear, and PTSD compared to the wait-list condition. Further, those in the family component of TFCBT demonstrated lower fears compared to the child only TFCBT condition at the three-month follow-up.

Overall, TF-CBT has been shown to be an effective treatment for child and adolescent victims of CSA. As noted by Paul, Gray, Elhai, Massad, and Stamm (2006) and Cohen and Mannarino (1998), benefits of TF-CBT include: reductions in depression; increased social competence; reductions in shame, abuse-related attributions, and behavior problems; increased knowledge of body safety skills; and cognitive reframing to address selfblame, feelings of powerlessness and hopelessness, and sexualized behaviors. While TF-CBT is typically conducted individually, it has also been administered in group, family therapy, and in school-based and office-based settings (Cohen \& Deblinger, 2004; Cohen et al., 2000).

A second time-limited individual intervention utilized with child and adolescent victims of CSA that has been shown to be acceptable and supported (Saunders et al., 2004) is Eye Movement Desensitization and Reprocessing (EMDR; Shapiro, 1995). Based on adaptive cognitive network theories of emotion and learning, and Piagetian views of accommodation and assimilation, EMDR is a multicomponent procedure used to address traumatic memories and PTSD symptoms typically in two to three sessions (Chemtob, 2004). The goals of EMDR include restarting and facilitating the blocked processing of the traumatic memory; promoting more adaptive cognitions about the trauma; and installing alternative positive cognitions, adaptive behaviors, and coping strategies that include relaxation and identifying a "safe place."

Originally developed for adults with PTSD symptoms, Chemtob (2004) reported that three controlled studies have been conducted with youth demonstrating the efficacy of EMDR with this population. However, given that one study was conducted with children with disaster-related PTSD and two other studies with children and young adults with various clinical problems, more research on the effectiveness and efficacy of EMDR with child victims of CSA is needed. Also, the actual mode of action of EMDR is still relatively unknown, particularly given the brevity of sessions conducted to deal with such challenging symptoms and cognitions (Chemtob, 2004).

\subsubsection{Non-offending caregivers}

Often, when a child who has been sexually abused is most needing their mother, the mother's resources for coping with the disclosure and its aftermath are also being taxed (Corcoran, 1998). Swenson and Hanson (1998) noted several treatment needs that may be addressed through individual interventions with non-offending caregivers, especially for parents who have been unable to provide belief, support, and protection to their child. Mental health interventions may focus on strengthening the parent's support and belief, reducing the child's symptoms (e.g., anxiety, anger, depression), attend to the parent's symptomatology (e.g., PTSD, guilt, sadness), address feelings of isolation and stigma, and address the economic consequences commonly associated with intrafamilial CSA (Swenson \& Hanson, 1998). In addition, treatments for non-offending caregivers may contain similar elements of trauma-focused work, in order to reduce parental distress, as well as behavior management strategies to address challenging behaviors exhibited by the child victim (Berliner \& Elliott, 2002).

As noted, TF-CBT for CSA victims often includes a parent component, which may maximize treatment benefits for the child (Wolfe, 2006). In addition, TF-CBT also provides skills to the non-offending caregivers (e.g., psychoeducation, behavior management, safety skills to prevent future victimization for their children; Cohen \& Mannarino, 1996; Corcoran, 2004; Paul et al., 2006). In a study by Celano, Hazzard, Webb, and McCall (1996), 32 girls ages 8 to 13 years, and their non-offending mothers were randomly assigned to either eight sessions of CBT or TAU that was supportive and non-structured. Each session was $1 \mathrm{~h}$ in duration. For the child victims, the CBT sessions included topics such as self-blame, traumatization, sexualization, feelings about the offender, distrust, and powerlessness. The parent CBT sessions included topics such as decreasing global self-blame, reducing misattributions of blame, increasing communication skills, betrayal, developing a parental support system, perceptions of their own powerlessness, and parenting skills. While results demonstrated similar impact for reducing self-blame, powerlessness, PTSD symptoms, and externalizing and internalizing symptoms for child victims, parents in the CBT condition demonstrated greater reductions in self-blame, more reported optimism about their child's future, and greater parental support compared to the TAU condition (Celano et al., 1996).

In a study by Stauffer and Deblinger (1996) the efficacy of CBT was compared with a wait-list condition for non-offending mothers of children ages 2 to 6 years. The non-offending mothers reported significantly lower levels of avoidance of abuse-related cognitions and feelings, less distress, increased parenting skills, and reductions in their child's sexual behavior problems, following treatment. Gains were maintained 3 months after treatment. Further, Paul et al. (2006) noted that the benefits of TF-CBT for non-offending caregivers included reductions in self-reported depressive symptoms and abuse-related distress, increased effective parenting practices, and greater support of their traumatized child.

While behavioral parent training interventions are commonly used with families exhibiting physical abuse, educating non-offending caregivers of CSA victims with more effective parenting skills and communication is also often necessary. With the challenging behaviors that may continue to occur or develop following CSA, these interventions are worth briefly noting. Based on behavior theory that encompasses several treatment protocols (e.g., Barkley's Defiant Children (1997), and McMahon and Forehand (2003) Helping the Noncompliant Child), behavioral parent training is usually conducted over 12 to 16 weeks. These treatment packages typically involve teaching parents skills in order to increase child compliance, decrease disruptive behaviors, and minimize problematic interactions between the parent and child at home, as well as in other settings. Techniques such as utilizing token economies to reward appropriate behaviors, issuing effective commands, consistency in discipline (i.e., timeout), and daily practice of skills with homework assignments 
are common (Brestan \& Payne, 2004). In addition to learning parenting skills to reduce the child's disruptive behaviors, Parent-child Interaction Therapy (PCIT; Hembree-Kigin \& McNeil, 1995) also focuses on improving the parent-child relationship. As an empirically supported treatment for child victims of physical abuse (Chaffin \& Friedrich, 2004; Urquiza, 2004), PCIT may be applicable for CSA victims, between the ages of 2 and 8 years, particularly when the focus of intervention is to enhance the relationship between the child and the non-offending parent.

\subsubsection{Non-abused siblings}

Given the limited literature on crisis evaluations and interventions available to non-abused siblings, the risk of overlooking the distress experienced by these youth is potentially great. According to Baker et al. (2001), including siblings in treatment permits the family to realize the maximum benefits of therapy for the victim and also for each family member. In addition, the increased risk of victimization for siblings may warrant the need to monitor sibling interactions, as well as educate siblings about sexual abuse and prevention skills (Baker et al., 2001). Further, siblings may be involved in the investigative or court process and may experience continued concerns (e.g., anxiety, embarrassment and shame, and anger at their sibling, the offender, and even at their non-offending caregiver). However, without appropriate immediate and time-limited individual interventions created to address these concerns, this may unfortunately result in more severe symptomatology that may warrant more intensive treatment. In addition, Baker et al. (2001) proposed the need to help non-offending parents understand the value of such interventions for their nonabused children following disclosure.

\subsection{Group interventions}

Group interventions are considered by some to be the treatment of choice (e.g., Grayston \& DeLuca, 1995; Reeker \& Ensing, 1998), particularly for preadolescent and adolescent victims to target feelings of isolation, social stigmatization, and reduce desires for secrecy. As cost-effective and efficient ways to treat many with the fewest resources available, group interventions are frequently utilized with victims of CSA, as well as with non-offending family members to provide them with their own sources of support (e.g., Avinger \& Jones, 2007; Grayston \& DeLuca, 1995; Heiman \& Ettin, 2001; Reeker \& Ensing, 1998; Sturkie, 1994).

\subsubsection{Child victims}

For child victims of CSA, group therapy is typically initiated later in treatment, as this forum may advance gains made in individual therapy sessions (Lanktree, 1994). However, for some, group therapy is not advisable. According to Schetky (1988), group treatment is not appropriate for youth demonstrating severe acting out behaviors. Hecht et al. (2002) also noted that group therapy would not be appropriate for adolescents who are in crisis, exhibit conduct problems, suffer from severe depression or psychosis, engage in self-mutilation, or exhibit serious developmental delays. Thus, the need for a thorough evaluation and screening through the use of standardized measures and obtaining detailed psychosocial histories is important in order to determine appropriateness for group intervention (Silovsky \& Hembree-Kigin, 1994; Wolfe, 2006).

As noted by Hecht et al. (2002), not all teenage sexual abuse victims require treatment, provided that resistance, avoidance, and denial of symptomatology have been ruled out. However, group treatment has been widely endorsed for this age group given the developmentally-appropriate focus on the peer network and shift away from caregivers in their willingness to accept feedback and comments (e.g., Grayston \& DeLuca, 1995; Hecht et al., 2002; Sturkie, 1994). In a review of group treatments of different modalities, Sturkie (1994) noted that early treatment groups tended to focus on many of the child's immediate responses following disclosure, including: disbelief, rejec- tion, blame, abandonment, anger, low self-esteem, depression, loss, powerlessness, anxiety, sexualized behaviors, and court involvement. With increasing recognition of the severity of symptoms and varied impacts on victims, emerging trends in group therapy included more stringent and explicit screening criteria for group inclusion, as well as more structured groups of longer duration (Sturkie, 1994).

Many have examined the benefits of group therapy for child and adolescent victims of CSA. Critical elements of group therapy for this population include the opportunity to reduce the sense of stigma and isolation by creating a positive and safe environment to foster mutual self-disclosure, increase socialization, understand that CSA is a relatively common and shared experience, and provide the ability to learn by modeling positive coping strategies of other group members (Heflin et al., 2000; Silovsky \& Hembree-Kigin, 1994; Sturkie, 1994; Tourigny et al., 2005; Wanlass, Moreno, \& Thomson, 2006). By focusing on the child, group therapy can address feelings of being damaged, responsibility, blame, guilt about the abuse, shame, and secrecy (e.g., Silovsky \& Hembree-Kigin, 1994) and thereby serve as a buffer as feelings and issues can be discussed without as much disclosure as is common in individual therapy (Avinger \& Jones, 2007). Further, according to Corder, Haizlip, and DeBoer (1990), group psychotherapy provides a peer forum for the victimized child which is necessary for full recovery from CSA.

There are many group treatments that have been developed specifically for CSA victims (e.g., Avinger \& Jones, 2007; Corder et al., 1990; Deblinger et al., 2001; Friedrich, Luecke, Beilke, \& Place, 1992; Gagliano, 1987; Grayston \& DeLuca, 1995; Grosz et al., 1999; Reeker \& Ensing, 1998; Stauffer \& Deblinger, 1996; Tourigny et al., 2005; Zaidi \& Gutierrez-Kovner, 1995). Given the multitude of group treatments for CSA victims, the following section discusses general treatment approaches, modalities, and considerations, rather than providing an exhaustive list. The group intervention section will be structured by first describing several theoretical orientations used. Then, the various considerations for group treatment, including age range of participants, structured vs. unstructured groups, gender composition of group members and therapists, and topics will be discussed.

Group treatments for child victims of CSA have encompassed a variety of theoretical models. In a review of group treatments, conducted between 1985 and 2005, Avinger and Jones (2007) found that only ten studies specifically addressed group therapy for girls, ages 11 to 18 years, who were victims of CSA. Over those ten studies, seven different theoretical models were used (e.g., TF-CBT, psychodrama, multidimensional, Rogerian, Eriksonian, dynamic, and unspecified, but included sex education). To determine the efficacy of these group treatments, various symptoms were measured, including PTSD, general anxiety, depression, self-esteem, conduct problems, and knowledge of sex education and coping skills.

Avinger and Jones (2007) found that both TF-CBT and multidimensional groups may be more effective in reducing symptoms of PTSD. The multidimensional groups encompassed three main components: skills (e.g., relaxation, assertiveness, social skills, problem solving), psychotherapeutic components (e.g., exposures), and education (e.g., sex education, shame and betrayal). In addition, children in the psychodrama groups demonstrated reductions in depressive systems. These psychodrama groups provided children with the opportunity to process their trauma by staging, directing, and acting out what had occurred, as well as provide them with bonding experiences with other group members. Across all groups, none of the models demonstrated any reductions in problem behaviors, which is consistent with individual therapy for children when treatment is not also provided to the non-offending caregivers. Regarding changes in self-esteem, all of the groups demonstrated significant improvements.

Finally, groups that focused on disseminating sex education were shown to increase the child's knowledge of sexual anatomy and physiology, as well as decrease feelings of guilt and shame. 
Overall, Avinger and Jones (2007) noted that the selection of the theoretical model may be important to consider given the different benefits that each can provide. However, it is noteworthy to consider that only four of the ten studies included a control or comparison group, and that studies varied considerably regarding such factors as group size, location of treatment, sources of referrals for treatment, and length and number of sessions.

Based on the literature on group treatments for child and adolescent victims, TF-CBT has been widely studied and shown to be effective in addressing symptoms associated with CSA (e.g., Cohen, Mannarino, Murray, \& Igelman, 2006; Deblinger et al., 2001; Saywitz et al., 2000). In a review article by Saywitz et al. (2000), several outcome studies were discussed that utilized CBT, in comparison to other treatment models, including nondirective and nonspecific treatments that are commonly used in community clinics. Across the studies reviewed, CBT and behavioral interventions were shown to be effective in reducing such symptoms as depression (Deblinger et al., 2001), PTSD (Cohen \& Mannarino, 1998), and sexually inappropriate behaviors (Cohen \& Mannarino, 1996).

The OVC guidelines (Saunders et al., 2004), identified CBT and Dynamic Play Therapy as two additional group treatment approaches developed for children, ages 6 to 12 years, with sexual behavior problems, and their non-offending caregivers. The cognitive-behavioral approach for sexual behavior problems is a 12-session, highly structured group treatment that includes such components as: learning and applying Sexual Behavior Rules, learning age-appropriate sex education, impulse control, positive reinforcement, cognitive reframing, and participation of non-offending caregivers for supervising their child and learning behavior management techniques (Bonner, 2004). While dynamic play therapy is also geared towards reducing inappropriate aggressive sexual behaviors over 12 sessions, this approach is based on client-centered and psychodynamic play principles (Bonner, 2004). Treatment components for dynamic play therapy include: use of acceptance, reflection, and interpretation to assist the child; facilitating the group interaction to improve peer relationships; and encouraging interaction among parents. While dynamic play therapy has been shown to be equally effective as CBT in reducing sexual behavior problems in a two-year follow-up study (Bonner, 2004), some believe play therapy may not be as therapeutic for children who have been severely traumatized, as they may reenact their trauma repeatedly through play (Schetky, 1988).

Across the different theoretical orientations for group interventions for CSA victims the following topics are typically covered: reactions to disclosure, guilt and responsibility, secrets, sex education, body image, private parts, good touches/bad touches, anger control, problem-solving skills, assertiveness, coping skills, peer relations, anxiety management, depression, self-esteem, behavior management, free play for preschoolers, and discussion of abuse experiences, offenders, and court processes (Reeker \& Ensing, 1998; Silovsky \& Hembree-Kigin, 1994; Stauffer \& Deblinger, 1996). In addition to topics, many groups have incorporated a shared snack time, in efforts to promote group cohesion, and help to nurture group members (e.g., Silovsky \& Hembree-Kigin, 1994; Sturkie, 1994; Zaidi \& GutierrezKovner, 1995). Further, a graduation or clear termination session is typically used, in order to prepare the child for transition after group and provide closure (e.g., Sturkie, 1994; Zaidi \& Gutierrez-Kovner, 1995). With TF-CBT groups, sessions may include telling and processing the trauma, graduated exposures, cognitive restructuring, and coping skills, such as relaxation skills (Avinger \& Jones, 2007). Other groups that are less structured, such as NST, that follow the self-help group model, may focus more on creating a supportive environment and allowing group members to decide what topics should be addressed (e.g., Deblinger et al., 2001).

Along with topics covered, the number and length of time of sessions may vary considerably. Across the different theoretical models reviewed by Avinger and Jones (2007), sessions var- ied from 6 to 24, with length of sessions ranging from 1 to $5 \mathrm{~h}$. According to Reeker and Ensing (1998), longer treatments may demonstrate better gains, with 12 to 24 sessions to reduce clinically significant symptoms into the normal range of functioning. Overall, regarding length of sessions, a review of group treatments for sexually abused children by Sturkie (1994) found that 90 min may be optimal.

Groups for CSA victims may also be either open- or closeended. As noted by Grosz et al. (1999), open-ended groups provided families with the benefits of receiving support from those who had made progress in their recovery. In addition, these experienced families could better appreciate the progress they had made when they were able to extend their support to newer group members. However, for child and adolescent group members, an open-ended format may present difficulties with building rapport and comfort discussing topics with newer group members.

The composition of the group is also an important factor for consideration. Separate groups have been developed based on age of the child, specifically for preschoolers, school-aged children, and adolescents (Sturkie, 1994). However, separate groups based also on developmental understanding should be considered. As noted by Sturkie (1994), a developmental range no more than 2 to 4 years may be most advantageous for group members. This developmental range may result in optimal benefits for group members, and inform how to adjust information that is being discussed, as with sex education. In addition, gender composition must be considered. According to Sturkie (1994), same-sex groups may be better. Given the sensitivity of topics that are covered (e.g., discussing the trauma, sex education) group members may be uncomfortable sharing and discussing topics with children of the opposite gender, particularly after pubertal age.

Further, the number of participants per group has been examined. Several studies have noted that six to eight participants may be optimal (Schetky, 1988; Sturkie, 1994). Across studies that were reviewed by Avinger and Jones (2007), group size varied from 4 to 16 adolescents. The size of the group may matter, specifically for fostering intimacy of the group and the amount of individual attention group members receive. These benefits may be minimized with larger groups. However, larger groups may afford greater opportunities for the normalization of each group member's experiences (Avinger \& Jones, 2007).

While the location of services is important to consider across the different modalities of treatment (i.e., crisis, short-term, longer-term), given the duration of group therapy that may span weeks to months, these services must be particularly accessible in order to reduce potential group attrition. In addition, conducting services in a child-friendly facility may further reduce the anxiety experienced by the child or adolescent victim, as well as their non-offending caregiver in presenting to group treatment. By conducting group therapy in an area accessible to public transportation, group attendance may be facilitated, especially given that only about $50 \%$ of clients have been shown to follow-through on referrals (Newman, Dannenfelser, \& Pendleton, 2005).

Lastly, characteristics of the group therapists should also be considered (e.g., Silovsky \& Hembree-Kigin, 1994; Sturkie, 1994). Sturkie (1994) suggested that it is essential for a successful group experience to have multiple facilitators for each group, given neediness of the child clients, need for immediate feedback, and potential absences of the group therapists. In addition, there are concerns utilizing mixed-gender facilitation teams, as having a male therapist for a group of female victims may not be accepted by the group, or become problematic as with triangulation of relationships within the group (Sturkie, 1994). Thus, Sturkie (1994) recommended that it would be best to use samesex facilitation teams. However, others such as Schetky (1988) have noted that a male co-therapist may actually help victims overcome the distrust they may feel towards males and learn to relate to males in an appropriate, nonsexual way. Grayston and 
DeLuca (1995) also suggested that having one male and one female therapist may be the best approach for male CSA victims.

\subsubsection{Non-offending caregivers}

According to Sturkie (1994), parallel treatment groups for parents emerged in the 1980s and focused on treatment of the child, as well as addressed issues that concerned the adult participants. Given that non-offending caregivers typically feel initially immobilized and overwhelmed following disclosure, and often experience a loss of trust in the safety of others, Grosz et al. (1999) noted the need many have to speak with other supportive adults. In addition, as the full extent of their anger and distress should not be expressed in the presence of their child, having a supportive group of other non-offending caregivers provides this outlet (Grosz et al., 1999). Essentially, group treatment may offer non-offending caregivers with a "lifeline" when they feel most isolated and disconnected from their normal support systems (Grosz et al., 1999; Schetky, 1988). Whether nonoffending caregivers may need assistance in dealing with their own abuse histories; feelings of anger, guilt, or self-blame; or learn how to manage their child's sexually inappropriate behaviors, group treatment may provide an appropriate and effective environment to address these issues.

Lomonaco, Scheidlinger, and Aronson (2000) summarized several advantages of group therapy for non-offending caregivers, including: provision of emotional support, learning new parenting skills, enhancing motivation in their support of the children's group work, and providing the opportunity to share information about the child's daily functioning. Grosz et al. (1999) also found that following participation in group treatment, non-offending caregivers demonstrated a decrease in anger, anxiety, sadness, and guilt. They also reported a renewed confidence in their parenting abilities as well as a restored sense of normalcy and pleasure in daily activities and routines. In addition, co-joint therapy for non-offending caregivers may decrease premature drop-out for the child (Celano et al., 1996).

According to the OVC guidelines, Johnson (2004) noted that Parents United (Child Sexual Abuse Treatment Program, CSATP), a direct clinical services and non-clinical support treatment program, designed for families affected by parent-child incest, was shown to be promising and acceptable. Based on the premise that all individuals are affected by the sexual abuse, Parents United assumes that all would benefit from interventions that are supportive. Most of the groups offered, including the Parent Group, are open-ended groups that meet for eight weeks, once a week and focus on psychoeducation, cognitive behavioral techniques, enhancement of interpersonal skills, and providing support. In addition, the Parent Group focuses on improving parenting skills, discussing their child's abuse, psychoeducation about the impact and dynamics of abuse, providing information and access to other resources, and allowing them to ventilate their own feelings (Johnson, 2004). Along with the clinical component, Parents United offers non-clinical supports (e.g., childcare, transportation for children, and big brother/big sister relationships) and self-help components (Giarretto, 1982). While Parents United also provides treatment for adult and adolescent offenders and adult victims, and is noted as a promising treatment program that is comprehensive, its inclusion here is as a group service for non-offending caregivers, which provides a peer forum for adults to discuss and vent their own feelings.

In a review of the literature, group factors for non-offending caregivers have also been examined. Lanktree (1994) noted that, in general, groups for non-offending mothers have typically followed a two-stage model. During the first phase, conducted over 8 to 12 weeks, sessions may focus on parent education, support, sexual abuse information, family dynamics (for intrafamilial CSA), coping skills, and an initial exploration of the non-offending parent's own victimization history. Over the second phase, the group may generally consist of the same members, but focus in greater depth on such issues as abuse histories and the associated trauma, sexuality, relationships, and identity issues.

Grosz et al. (1999) required the non-offending parent to participate in a Parent Support Group if their child was enrolled in the Children's Group. These groups were open-ended and met simultaneously with the children's treatment groups, for $90 \mathrm{~min}$ over 6 to 9 months. The number of participants per session was limited to three to eight caregivers. Following the group treatment, parents reported reductions in anxiety, sadness, guilt, and anger, and increased confidence in parenting abilities. However, parents were permitted to extend their participation in group therapy if needed. Thus, Grosz et al. (1999) suggested that an alternative, short-term but focused group with clearly defined goals, expectations, and limitations may be more successful.

In a study examining the effectiveness of CBT vs. NST groups for caregivers, Deblinger et al. (2001) assigned 44 non-offending mothers and their 44 children who had experienced CSA to either 11 weeks of 2-hour sessions of CBT or 11 weeks of 90-minute sessions of NST. CBT modules consisted of those noted in Stauffer and Deblinger (1996), with co-joint parent-child activities. While the NST group was manualized, only the first session was similar to CBT and the rest similar to a self-help group. Although parents demonstrated benefits from both groups, CBT was shown to have superior outcomes as compared to the NST group. However, limitations of the study included no control group, as well as the sub-clinical behavioral problems exhibited by the children at pre-treatment.

Overall, group treatment with non-offending caregivers appears to have many benefits, especially with increasing the support and recovery of their children, decreasing attrition from treatment, addressing behavioral difficulties, providing a supportive environment where caregivers can address their own emotional and psychological distress, and opportunities to model more effective coping strategies demonstrated by other group members (e.g., Corcoran, 2004; Lomonaco et al., 2000). However, as noted by Elliott and Carnes (2001), while there are a wide range of interventions developed for non-offending caregivers, there continue to be few rigorous studies completed. Specifically, few studies have examined additional variables, other than theoretical models, in understanding what group interventions would be most beneficial for non-offending caregivers (e.g., number of therapists, open- vs. close-ended groups, and number of sessions).

\subsubsection{Non-abused siblings}

As noted previously, there are many reasons siblings may necessitate their own mental health interventions, including their own emotional distress, experiencing secondary traumatization, and being at increased risk for victimization. Nonabused siblings may also face stigma and shame, which can be addressed in a group environment affording them the opportunity to realize that CSA has also occurred in other families (Baker et al., 2001). Unfortunately, the number of group treatments offered to non-abused siblings is markedly lacking in the literature. As noted, non-offending caregivers may need to be shown the value of incorporating the non-abused siblings in treatment (Baker et al., 2001). The sole published study that focused on providing group therapy to non-abused siblings was conducted by Baker et al. (2001) at the Family Learning Program for intrafamilial CSA families. Sibling groups were held simultaneously with the child victim, adolescent victim, and non-offending caregiver's groups, which alleviated the stress of needing childcare, as well as not needing to make multiple trips to treatment in the same week. Through the siblings group, child abuse prevention skills were taught and psychoeducation provided that included: defining sexual abuse, private body parts, good/bad touches, secrets, personal space, sex education, recognizing inappropriate touches, tricks used by perpetrators, assertiveness, and problem solving skills. These groups also provided the non-abused siblings with the opportunity to learn important social skills that may have been lacking in their families, as well 
as afforded facilitators the opportunity to monitor the difficulties and adjustment experienced by the siblings. Conducted by two group facilitators, the siblings group utilized play materials, games, art, free time, and snack time.

Since its inception in 1992 to 2001, the Family Learning Program (Baker et al., 2001) has provided group treatment services to over 110 siblings. However, as noted by Baker et al. (2001), more rigorous outcome studies and program evaluations are needed in order to demonstrate the effectiveness and limitations of siblings groups. Given the numerous issues siblings may face, "leaving siblings out of the treatment program is neglectful at best and dangerous at worst" (Baker et al., 2001, p. 11).Also, as noted by Baker et al. (2000), when conducting a siblings group, considerations that need to be made that may be challenging, include the need for additional materials and therapy rooms, need for additional therapists, and number of participants so groups can be divided appropriately based on developmental level.

\subsection{Need for long-term interventions and referrals}

While group therapy has been shown to provide many benefits for group members, Schetky (1988) noted that it is not intended to alter any underlying psychopathology that may have preceded the CSA. Further, group therapy may be insufficient as it is fundamentally not tailored to meet each child's unique needs (Grayston \& DeLuca, 1995). As there may be many factors that predispose a child to becoming a victim of CSA (Schetky, 1988), as well as parental or family factors that may be risk factors for the abuse and/or revictimization, long-term interventions may provide the opportunity to focus on either long-term symptomatically-focused treatment or more in-depth reconstructive treatment (Hecht et al., 2002). The following section will briefly identify symptoms and other concerns that may prompt referrals for long-term and more intensive therapy than can be provided through time-limited individual or group interventions.

For child victims of CSA, several long-term effects have been noted, including anxiety, depression, suicide ideation, self-injurious behaviors, substance abuse, and conduct problems (e.g., Swanston et al., 2003; Wolfe, 2006). In order to deal with the longterm symptomatology commonly associated with CSA, as well as children who present with multiple concerns, various interventions may be utilized that are variable in length. While there are several empirically supported treatments for specific disorders or diagnoses (e.g., CBT for depression and anxiety), there are also long-term interventions that are specific for abuse-related symptoms. With the need for longer-term interventions and provision of referrals, contact with community agencies is important, given that these services are not feasible to conduct at CACs.

Given the severity of symptoms non-offending caregivers may display (e.g., suicide attempts, secondary trauma, eating disturbances, generalized fears), up to an average of two years following the initial disclosure (Deblinger et al., 1993; Regehr, 1990), more accessible and long-term interventions may be needed. For such diagnosable psychological disorders as depression, anxiety, and PTSD, appropriate and empirically supported interventions are available. Additionally, non-offending caregivers may benefit from more intensive individual services to address their own histories of trauma. As there is no set symptomatology for victims or non-offending caregivers following disclosure of CSA, the crisis, time-limited individual, and group interventions may be sufficient to address many of the presenting concerns. Although there are numerous family reunification interventions documented in the literature, these are beyond the scope of the present paper due to their focus on treatment for offenders.

As discussed in previous sections, non-abused siblings may also experience significant psychological distress and psychosocial challenges that necessitate therapeutic interventions (Baker et al., 2001; Grosz et al., 1999). Unfortunately, without proper examination of the short- and long-term effects of CSA on non-abused siblings, and overall limited attention paid to the needs of non-abused siblings, these children will continue to be underserved.

\section{A model for mental health services in child advocacy centers}

Given the diverse needs of child victims and/or their non-offending family members, a continuum of accessible treatments is imperative. Currently, a paucity of studies exist which examine the efficacy of CSA treatments in reducing symptoms or improving adaptive functioning in these populations (Celano et al., 1996). Further, while CACs increasingly provide on-site mental health services for sexually abused youth, little is known about the types of services available. The following section will provide an overview of Project SAFE (Sexual Abuse Family Education), a cognitive-behavioral treatment program for sexually abused youth that may serve as a model for mental health services in CACs.

Project SAFE was established at the University of NebraskaLincoln in 1996 by David Hansen and members of his Child Maltreatment Lab. After the establishment of the Lincoln/Lancaster County Child Advocacy Center in 1998, the need for prompt, on-site mental health services that would be accessible to child victims and their non-offending family members was evident. To respond to these needs, Project SAFE began on-site mental health services at the CAC in 2000. Project SAFE offers families four different manualized cognitive-behavioral interventions which are selected according to the presenting needs of the families.

\subsection{Project SAFE: Group treatment for sexually abused youth and their non-offending caregivers}

The Project SAFE Group Intervention was developed in 1996 and group services are now offered year-round to families. The Project SAFE Group Intervention was designed to address three critical target areas impacted by sexual abuse: (a) the individual or self (e.g., self-esteem, internalizing distress); (b) relationships (e.g., social support, communication, externalizing problems with peers and family); and (c) sexual development (e.g., sexual knowledge and abuse-related issues; Hansen, Hecht, \& Futa, 1998). The Project SAFE Group Intervention is a standardized 12-week, cognitive-behavioral treatment for sexually abused youth (ages 7-18) and their non-offending parents. Given that group treatments are more effective when clients are closer in age and developmental level (e.g., Avinger \& Jones, 2007; Corder et al., 1990), Project SAFE groups often consist of one group of child victims (ages 7-12 years), and a separate group of adolescent victims (ages 1318 years). Project SAFE utilizes a parallel design, whereby youth and parent groups meet separately, but concurrently to discuss similar topics in developmentally appropriate ways. Each session is $90 \mathrm{~min}$, and groups are co-facilitated by therapists who are doctoral students in the Clinical Psychology Training Program at the University of Nebraska-Lincoln, and supervised by licensed clinical psychologists.

Techniques for the Project SAFE Child and Adolescent Groups include: (a) psychoeducation (e.g., good/touches, personal space, sexual education, why offenders offend); (b) the identification and regulation of feelings; (c) cognitive restructuring of maladaptive thoughts; (d) relaxation techniques; (e) disclosure of abuse and the impact of CSA on their family; and (f) strategies to prevent revictimization (e.g., problem-solving, assertiveness skills).

Due to the parallel nature of the Project SAFE Group Intervention, the Non-Offending Caregiver Group covers similar topics at an advanced developmental level. Caregiver topics include, but are not limited to, the following: (a) psychoeducation (e.g., the prevalence of sexual abuse, why offenders offend); (b) affective regulation following the disclosure of abuse; (c) cognitive restructuring of maladaptive thoughts (e.g., "I should have noticed the abuse was happening sooner"); (d) relaxation 
techniques; (e) effective communication strategies, particularly abuse-related communication; (f) disclosure of abuse and the impact of CSA on their family; and (g) prevention of revictimization strategies (e.g., safety planning). It should be noted that referrals for additional mental health services are provided throughout the group if necessary (e.g., significant behavioral problems, substantial parent-child conflict).

\subsection{Project SAFE: Group treatment for non-abused siblings}

In response to the growing needs of non-abused siblings, a Project SAFE Group Treatment for Non-Abused Siblings was developed in 2004. This 6-week, parallel group treatment (i.e., victim, caregiver, and siblings groups meet concurrently but separately) meets for, 90 min each week. The group is offered to youth ages 7 to 18 years and topics include: (a) psychoeducation (e.g., what is sexual abuse, personal space, sexual education); (b) the identification and regulation of feelings; (c) cognitive restructuring of maladaptive thoughts; (d) relaxation techniques; (e) the impact of CSA on their family; and (f) strategies to prevent victimization (e.g., problem-solving, assertiveness skills). With participants of varying developmental levels, information is modified to be appropriate for each group member, and at times specific components of a given module (e.g., sex education) have been conducted individually or with same-gender group members.

As with the Child and Adolescent Groups, same-sex therapists cofacilitate the group, unless benefits of a male co-therapist are deemed to be helpful. Prior to each session, brief check-ins with the Parent Group are provided with one of the co-therapists in each of the Child, Adolescent, and Sibling Groups, which provides the caregivers with opportunities to share any concerns they may have with the material before it is provided to their children. An age-appropriate prize and small snack are provided to each youth group member at the end of each session in order to reward appropriate group behaviors. At the conclusion of the 12-session Project SAFE Group Intervention, a party with refreshments and personalized certificates of completion are provided, and is attended by all of the group therapists. Throughout the group, free childcare by undergraduate assistants and snacks are provided to younger siblings who are not eligible for group services. These efforts help to maintain low attrition.

\subsection{Project SAFE: Crisis intervention}

As the need for Project SAFE Group Intervention services increased, so did the need for more accessible interventions for families in crisis. In response, the Project SAFE Parent Support and Education Session (PSES) was developed in 2002 to provide a single crisis session to help non-offending caregivers process and cope with the immediate challenges that commonly occur following the disclosure of abuse.

Although manualized, the PSES affords more individualized and flexible treatment than the Group Intervention. The PSES protocol includes specific modules that are selected by the therapist to best meet the client's presenting needs. This single session crisis intervention may vary in length from 1 to $3 \mathrm{~h}$. Topics in the Project SAFE PSES protocol include: prevalence of CSA, how sexual abuse may affect their child, how sexual abuse will affect them as a parent, common reactions, briefly processing the caregiver's own abuse history if applicable, sensitive listening and responding to their child, prevention skills for future abuse, effects on the non-abused siblings, benefits of group therapy, assessment of risk, appropriate and inappropriate sexual behaviors, and provision of referrals if applicable.

\subsection{Project SAFE: Brief family intervention}

While the Project SAFE Group Intervention has been helpful in providing cost- and time-effective services, CAC staff members were routinely presented with victims and families in need of services while the Group Intervention was already underway.
While non-offending caregivers have reported benefiting from the Project SAFE PSES, for many, this service was insufficient, as many reported concerns about their sexually abused child and/ or the non-abused siblings, uncertainties on how to approach topics directly with their children, and the need for multiple sessions for themselves. Thus, the Project SAFE Brief Family Intervention (BFI)was developed to provide short-term, $1 \mathrm{~h}$, three to six sessions, treatment that involved individual and family counseling for sexually abused children and their non-offending caregivers. Each BFI is conducted by a separate therapist for each family member, allowing for individualized sessions that meet concurrently. Session topics included in the Project SAFE BFI are essentially brief versions of the modules noted in the Group Intervention. The BFI affords some flexibility in individualizing sessions. Given the limited number of non-abused siblings referred for BFI services, modules from the caregiver and victim manuals continue to be examined and applied as appropriate in order to develop a BFI manual for non-abused siblings. As all Project SAFE services are time-limited, referrals to community agencies are routinely provided to victims and non-offending family members after the termination of services, which include referrals for individual therapy that may be more abusefocused, behavioral management skills for parenting, couples therapy, and family counseling. Families are also referred to the Project SAFE Group Intervention when appropriate.

\subsection{Project SAFE: Benefits and treatment gains}

The development of the varied Project SAFE services has largely been guided by the recognized need for mental health interventions for victims and their non-offending family members in order to meet the needs of such a heterogeneous group of individuals (e.g., Hansen et al., 1998). Through the four different Project SAFE interventions, there is a greater ability to triage care as soon as possible based on individual presenting needs. Further, given how critical the support of non-offending family members is for the victims of sexual abuse (Berliner \& Elliott, 2002; Conte \& Schuerman, 1987), the availability of immediate and varied mental health services is of great importance. In addition, through an initial evaluation, that includes a discussion with CAC advocates about the appropriateness of referrals (i.e., children with primarily sexual behavior problems, no identified offender, and severe developmental delays are immediately provided with referrals to community agencies) and meeting between the family and the Project SAFE Program Coordinator, clinical services are quickly triaged in efforts to best meet the presenting needs.

In comparison to currently available local community resources, Project SAFE offers several unique advantages for families, including: free multiple-session therapy, parallel group therapy for non-offending family members, education tailored to help prevent revictimization, free child care for younger children, and flexible scheduling for appointments that include evenings. Project SAFE is also the only community resource available for non-abused siblings that addresses their unique emotional needs and offers support through group sessions with same-aged peers. Thus, Project SAFE offers services at the $\mathrm{CAC}$ at no cost that are otherwise unavailable and assists in creating awareness of the importance of psychological services for non-offending family members in addition to child victims after disclosure of sexual abuse.

Project SAFE interventions are continually being monitored through ongoing assessment of participants using multiple selfand parent-report standardized instruments (Hansen et al., 1998; Hsu, Sedlar, Flood, \& Hansen, 2002; Hubel, Maldonado, Tavkar, Hansen, \& Flood, in press). Parents report post-group treatment improvements in child behaviors and functioning, specifically with less anxiety, increased basic sexual knowledge, less posttraumatic stress symptoms, less negative perceptions of social reactions, and less maladaptive abuse attributions (Hsu, 2003). These treatment gains were maintained 3 months after comple- 
tion of the group intervention. Campbell et al. (2006) and Sawyer et al. (2005) also found similar treatment gains for child group members, with increased self-esteem, and fewer behavior problems and inappropriate sexual behaviors reported by their non-offending caregivers. Further, Sawyer and Hansen (submitted for publication) noted that all group members evidenced a decrease in symptoms over the course of treatment, including those who had reported subclinical symptoms at pretreatment. Given the varied needs of those who present for mental health services on-site at CACs, Project SAFE may be a model program to implement throughout other CACs nationwide.

While it is common for CACs to rely on community agencies to access mental health services for families, the present partnership allows CAC staff to immediately access on-site services, thereby avoiding such difficulties for clients as waiting lists, fees for services as many individuals may not have mental health diagnoses that would be covered through insurance, lack of access to free childcare, and transportation costs. As noted, providing the opportunity to promptly access these services within a CAC, a child-friendly location that is already familiar to the family, may be most favorable for identifying those in need, providing effective and prompt interventions, decreasing attrition in treatment, and providing referrals as needed.

\section{Recommendations and future directions}

Based on a review of the literature, many child victims and their non-offending family members may present with various psychosocial difficulties following disclosure. Given complexities in symptom presentation and the need for more heterogeneous interventions, the following recommendations for future research and clinical practice are provided. First, CACs should continue to be used as initial access sites for the provision of mental health services for families dealing with CSA. By promptly assessing the needs of the abused child and non-offending family members, through standardized and validated assessment measures, any potential harm and discomfort experienced upon initial presentation can be reduced through provision of appropriate interventions, which is the mission of the CAC model. This immediate access to families also provides an ideal opportunity to educate non-offending caregivers on the impacts of CSA on not only the child victim, but also themselves and their non-abused children.

Second, the collaboration between mental health professionals at CACs and other mental health agencies should be strengthened. Given the onset and severity of distress and symptoms experienced by victims and non-offending family members, knowledge of appropriate community agencies that provide a variety of accessible services is important. Particularly given the challenges faced by many of these families (e.g., limited financial resources, difficulties securing childcare, difficulties with transportation, limited proficiency in English), providing referrals to agencies with sliding-fee scales, free-childcare, and access to translators or bilingual therapists, should also be considered.

Third, more research is warranted to identify the heterogeneous impact of CSA on non-offending caregivers, and particularly non-abused siblings who are unfortunately overlooked. Through a better understanding of the impact of CSA on nonoffending family members, more effective and accessible interventions may be developed and tailored. While many treatments may be available, the number of efficacious interventions is rather limited. Further, no algorithm has been developed or rigorous research conducted to most effectively triage care. As noted with Project SAFE services, interventions are triaged primarily based on clinical judgment. Thus, more research is needed to better understand what factors may result in more effective treatment and the reduction of symptoms.

This manuscript provides a novel review of interventions based on the need for services and highlights the necessity to immediately triage care. In addition, various treatment considerations have been examined. However, given the continued prevalence of CSA, and recognized heterogeneous impact on victims, non-offending caregivers, and non-abused siblings, the need to provide prompt, accessible, and effective interventions remains given the limited rigorous studies that have been conducted to date on treatments specific to these populations. Project SAFE has been provided as an example program which focuses on meeting these needs.

\section{References}

Avinger, K. A., \& Jones, R. A. (2007). Group treatment of sexually abused adolescent girls: A review of outcome studies. The American Journal of Family Therapy, 35, 315-326.

Baker, J. N., Tanis, H. J., \& Rice, J. B. (2001). Including siblings in the treatment of child sexual abuse. Journal of Child Sexual Abuse, 10, 1-16.

Barkley, R. A. (1997). Defiant children: A clinician's manual for assessment and parent training. New York: Guilford Press.

Beitchman, J. H., Zucker, K. J., Hood, J. E., daCosta, G. A., \& Akman, D. (1991). A review of the short-term effects of child sexual abuse. Child Abuse \& Neglect, 15, 537-556.

Beitchman, J. H., Zucker, K. J., Hood, J. E., daCosta, G. A., Akman, D., \& Cassavia, E. (1992). A review of the long-term effects of child sexual abuse. Child Abuse \& Neglect, 16, 101-118.

Berliner, L., \& Elliott, D. M. (2002). Sexual abuse of children. In J. E. B. Myers, L. Berliner, J.

Briere, C. T. Hendrix, C. Jenny, \& T. A. Reid (Eds.), The APSAC handbook on child maltreatment (pp. 55-78). (2nd ed.). Thousand Oaks, CA: Sage.

Bonner, B. (2004). Cognitive-behavioral and dynamic play therapy for children with sexual behavior problems and their caregivers. In B. E. Saunders, L. Berliner, \& R. F. Hanson (Eds.), Child physical and sexual abuse: Guidelines for treatment (pp. 34-36). Charleston, SC: National Crime Victims Research and Treatment Center.

Brestan, E., \& Payne, H. (2004). Behavioral parent training interventions for conduct-disordered children. In B. E. Saunders, L. Berliner, \& R. F. Hanson (Eds.), Child physical and sexual abuse: Guidelines for treatment (pp. 61-65). Charleston, SC: National Crime Victims Research and Treatment Center.

Campbell, C., Wilson, K., Evans, S., Sawyer, G. K., Tavkar, P., \& Hansen, D. J. (2006, November). Heterogeneity of psychological and behavior symptom presentation in sexually abuse youth: Three months post treatment. Poster presented at the Association for Behavioral and Cognitive Therapies, Chicago, IL.

Celano, M., Hazzard, A., Webb, C., \& McCall, C. (1996). Treatment of traumagenic beliefs among sexually abused girls and their mothers: An evaluation study. Journal of Abnormal Child Psychology, 24, 1-17.

Chaffin, M., \& Friedrich, B. (2004). Evidence-based treatments in child abuse and neglect. Children and Youth Services Review, 26, 1097-1113.

Chemtob, C. (2004). Eye movement desensitization and reprocessing (EMDR). In B. E. Saunders, L. Berliner, \& R. F. Hanson (Eds.), Child physical and sexual abuse: Guidelines for treatment (pp. 39-42). Charleston, SC: National Crime Victims Research and Treatment Center.

Cohen, J. A., Berliner, L., \& Mannarino, A. P. (2000). Treating traumatized children: A research review and synthesis. Trauma, Violence, \& Abuse, $1,29-46$.

Cohen, J. A., \& Deblinger, E. (2004). Trauma-focused cognitive-behavioral therapy (CBT). In B. E. Saunders, L. Berliner, \& R. F. Hanson (Eds.), Child physical and sexual abuse: Guidelines for treatment (pp. 4951). Charleston, SC: National Crime Victims Research and Treatment Center.

Cohen, J. A., Deblinger, E., \& Mannarino, A. P. (2005). Trauma-focused cognitive-behavioral therapy for sexually abused children. In E. Hibbs and \& P. Jensen (Eds.), Psychosocial treatments for child and adolescent disorders: Empirically based strategies for clinical practice (pp. 743-765). (2nd ed.). Washington, DC: American Psychological Association.

Cohen, J. A., \& Mannarino, A. P. (1996). A treatment outcome study for sexually abused preschool children: Initial findings. Journal of the American Academy of Child and Adolescent Psychiatry, 34, 42-50.

Cohen, J. A., \& Mannarino, A. P. (1997). A treatment study for sexually abused preschool children: Outcome during a one-year follow-up. Journal of the American Academy of Child and Adolescent Psychiatry, 36, 1228-1235.

Cohen, J. A., \& Mannarino, A. P. (1998). Interventions for sexually abused children: Initial treatment outcome findings. Child Maltreatment, 3, $17-26$.

Cohen, J. A., Mannarino, A. P., Murray, L. K., \& Igelman, R. (2006). Psychological interventions for maltreated and violence-exposed children. Journal of Social Issues, 62, 737-766.

Conte, J. R., \& Schuerman, J. R. (1987). Factors associated with an increased impact of child sexual abuse. Child Abuse \& Neglect, 11, 201-211.

Corcoran, J. (1998). In defense of mothers of sexual abuse victims. Families in Society, 79, 358-369.

Corcoran, J. (2004). Treatment outcome research with the non-offending 
parents of sexually abused children: A critical review. Journal of Child Sexual Abuse, 13, 59-84.

Corder, B. F., Haizlip, T., \& DeBoer, P. (1990). A pilot study for a structured, time-limited therapy group for sexually abused pre-adolescent children. Child Abuse \& Neglect, 14, 243-251.

Deblinger, E., Hathaway, C. R., Lippman, J., \& Steer, R. (1993). Psychosocial characteristics and correlates of symptom distress in non-offending mothers of sexually abused children. Journal of Interpersonal Violence, 8, 155-168.

Deblinger, E., Lippman, J., \& Steer, R. (1996). Sexually abused children suffering posttraumatic stress symptoms: Initial treatment outcome findings. Child Maltreatment, 1, 310-321.

Deblinger, E., Stauffer, L. B., \& Steer, R. A. (2001). Comparative efficacies of supportive and cognitive behavioral group therapies for young children who have been sexually abused and their non-offending mothers. Child Maltreatment, 6, 332-343.

deYoung, M. (1994). Immediate maternal reactions to the disclosure or discovery of incest. Journal of Family Violence, 9, 21-31.

Elliott, A. N., \& Carnes, C. N. (2001). Reactions of non-offending parents to the sexual abuse of their child: A review of the literature. Child Maltreatment, 6, 314-331.

Finkelhor, D. (1990). Early and long-term effects of child sexual abuse: an update. Professional Psychology: Research and Practice, 21, 325-330.

Friedrich, W. N., Luecke, W. J., Beilke, R. L., \& Place, V. (1992). Psychotherapy outcome of sexually abused boys: An agency study. Journal of Interpersonal Violence, 7, 396-409.

Gagliano, C. K. (1987). Group treatment for sexually abused girls. Social Casework, 68, 102-108.

Giarretto, H. (1982). A comprehensive child sexual abuse treatment program. Child Abuse \& Neglect, 6, 263-278.

Grayston, A. D., \& DeLuca, R. V. (1995). Group therapy for boys who have experienced sexual abuse: Is it the treatment of choice? Journal of Child and Adolescent Group Therapy, 5, 57-82.

Grosz, C. A., Kempe, R. S., \& Kelly, M. (1999). Extrafamilial sexual abuse treatment for child victims and their families. Child Abuse \& Neglect, 24, 9-23.

Hansen, D. J., Hecht, D. B., \& Futa, K. T. (1998). Child sexual abuse. In V. B. Van Hasselt \& M. Hersen (Eds.), Handbook of psychological treatment protocols for children and adolescents (pp. 153-178). Mahwah, NJ: Lawrence Erlbaum Associates.

Hecht, D. B., Chaffin, M., Bonner, B. L., Worley, K. B., \& Lawson, L. (2002). Treating sexually abused adolescents. In J. E. B. Myers, L. Berliner, J. Briere, C. T. Hendrix, C. Jenny, \& T. A. Reid (Eds.), The APSAC handbook on child maltreatment (pp. 159-174). (2nd ed.). Thousand Oaks, CA: Sage.

Heflin, A. H., Deblinger, E., \& Fisher, C. D. (2000). Child sexual abuse. In F. M. Dattilio \& A. Freeman (Eds.), Cognitive-behavioral strategies in crisis intervention (pp. 166-195). New York: Guilford Press.

Heiman, M. L., \& Ettin, M. F. (2001). Harnessing the power of the group for latency-aged sexual abuse victims. International Journal of Group Psychotherapy, $51,265-282$.

Hembree-Kigin, T. L., \& McNeil, C. B. (1995). Parent-child interaction therapy. New York: Plenum.

Hill, A. (2003). Issues facing brothers of sexually abused children: Implications for professional practice. Child and Family Social Work, 8, 281-290.

Hsu, E. (2003). Parallel group treatment for sexually abused children and their non-offending parents: An examination of treatment integrity and child and family outcome and satisfaction. Unpublished doctoral dissertation, University of Nebraska, Lincoln.

Hsu, E., Sedlar, G., Flood, M. F., \& Hansen, D. J. (2002). Child sexual abuse. In M. Hersen (Ed.), Clinical behavior therapy: Adults and children (pp. 449473). New York: Wiley.

Hubel, G. S., Maldonado, R. C., Tavkar, P., Hansen, D. J., \& Flood, M. F. (in press). Group treatment for a sexually abused child and a non-offending caregiver: Case study and discussion. Clinical Case Studies.

Jackson, S. L. (2004). A USA national survey of program services provided by child advocacy centers. Child Abuse \& Neglect, 28, 411-421.

Jinich, S., \& Litrownik, A. (1999). Coping with sexual abuse: Development and evaluation of a videotape intervention for non-offending parents. Child Abuse \& Neglect, 23, 175-190.

Johnson, D. A. (2004). Parents United (Child Sexual Abuse Treatment Program). In B. E. Saunders, L. Berliner, \& R. F. Hanson (Eds.), Child physical and sexual abuse: Guidelines for treatment (pp. 86-89). Charleston, SC: National Crime Victims Research and Treatment Center.

King, N. J., Tonge, B. J., Mullen, P., Myerson, N., Heyne, D., Rollings, S., et al. (2000). Treating sexually abused children with posttraumatic stress symptoms: A randomized clinical trial. Journal of the American Academy of Child and Adolescent Psychiatry, 39, 1347-1355.

Lanktree, C. B. (1994). Treating child victims of sexual abuse. In J. Briere (Ed.), Assessing and treating victims of violence (pp. 55-66). San Francisco, CA: Jossey-Bass.
Lomonaco, S., Scheidlinger, S., \& Aronson, S. (2000). Five decades of children's group treatment: An overview. Journal of Child and Adolescent Group Therapy, 10, 77-96.

Manion, I. G., McIntyre, J., Firestone, P., Ligezinska, M., Ensom, R., \& Wells, G. (1996). Secondary traumatization in parents following the disclosure of extrafamilial child sexual abuse: Initial effects. Child Abuse $\mathcal{E}$ Neglect, 20, 1095-1109.

McMahon, R. J., \& Forehand, R. (2003). Helping the noncompliant child: Family-based treatment for oppositional behavior (2nd ed.). New York: Guilford Press.

National Children's Advocacy Center (2007). 2007 Annual Report. Retrieved April 2, 2009, from. http://www.nationalcac.org/ncac/NCAC_ AR2007.pdf.

Newberger, C. M., Gremy, I. M., Waternaux, C. M., \& Newberger, E. H. (1993). Mothers of sexually abused children: Trauma and repair in longitudinal perspective. American Journal of Orthopsychiatry, 63, 92-102.

Newman, B. S., Dannenfelser, P. L., \& Pendleton, D. (2005). Child abuse investigations: Reasons for using child advocacy centers and suggestions for improvement. Child and Adolescent Social Work, 22, 165-181.

Paul, L. A., Gray, M. J., Elhai, J. D., Massad, P. M., \& Stamm, B. H. (2006). Promotion of evidence-based practices for child traumatic stress in rural populations: Identification of barriers and promising solutions. Trauma, Violence, \& Abuse, 7, 260-273.

Putnam, F. W. (2003). Ten-year research update review: Child sexual abuse. Journal of American Academy of Child \& Adolescent Psychiatry, 42, 269-278.

Reeker, J., \& Ensing, D. (1998). An evaluation of a group treatment for sexually abused young children. Journal of Child Sexual Abuse, 7, 65-85.

Regehr, C. (1990). Parental responses to extrafamilial child sexual assault. Child Abuse \& Neglect, 14, 113-120.

Saunders, B. E., Berliner, L., \& Hanson, R. F. (Eds.). (2004). Child physical and sexual abuse: Guidelines for treatment (Revised report: April 26, 2004). Charleston, SC: National Crime Victims Research and Treatment Center.

Sawyer, G. K., \& Hansen, D. J. (submitted for publication). Heterogeneous symptom patterns of sexually abused youth in treatment: Understanding the complexity of the problem.

Sawyer, G. K., Yancey, C. T., Hsu Tsao, E., Wynne, A., Hansen, D. J., \& Flood, M. F. (2005, November). Parallel group treatments for sexually abused youth and their non-offending parents: Treatment integrity, outcomes and social validity of Project SAFE. Poster presented at the Association for Behavioral and Cognitive Therapies, Washington, DC.

Saywitz, K. J., Mannarino, A. P., Berliner, L., \& Cohen, J. A. (2000). Treatment for sexually abused children and adolescents. American Psychologist, 55, 1040-1049.

Schetky, D. H. (1988). Treatment of the sexually abused child. In D. H. Schetky \& A.H. Green (Eds.), Child sexual abuse: A handbook for health care and legal professionals (pp. 193-208). New York: Brunner/Mazel.

Shapiro, F. (1995). Eye movement desensitization and reprocessing: Basic principles, protocols, and procedures. New York: Guilford Press.

Silovsky, J. F., \& Hembree-Kigin, T. L. (1994). Family and group treatment for sexually abused children: A review. Journal of Child Sexual Abuse, 3, $1-19$.

Smith, D. W., Witte, T. H., \& Fricker-Elhai, A. E. (2006). Service outcomes in physical and sexual abuse cases: A comparison of child advocacy center-based and standard services. Child Maltreatment, 11, 354-360.

Stauffer, L. B., \& Deblinger, E. (1996). Cognitive behavioral groups for nonoffending mothers and their young sexually abused children: A preliminary treatment outcome study. Child Maltreatment, 1, 65-75.

Sturkie, K. (1994). Group treatment for sexually abused children: Clinical wisdom and empirical findings. Child and Adolescent Psychiatric Clinics of North America, 3, 813-829.

Swanston, H. Y., Plunkett, A.M., O'Toole, B. I., Shrimpton, S., Parkinson, P. N., \& Oates, R. K. (2003). Nine years after child sexual abuse. Child Abuse \& Neglect, 27, 967-984.

Swenson, C. C., \& Hanson, R. F. (1998). Sexual abuse of children: Assessment, research, and treatment. In J. R. Lutzker (Ed.), Handbook of child abuse research and treatment (pp. 475-499). New York: Plenum.

Tourigny, M., Hébert, M., Daigneault, I., \& Simoneau, A. C. (2005). Efficacy of group therapy for sexually abused adolescent girls. Journal of Child Sexual Abuse, 14, 71-93.

Urquiza, A. (2004). Parent-child interaction therapy (PCIT). In B. E. Saunders, L. Berliner, \& R. F. Hanson (Eds.), Child physical and sexual abuse: Guidelines for treatment (pp. 81-83). Charleston, SC: National Crime Victims Research and Treatment Center.

Wanlass, J., Moreno, J. K., \& Thomson, H. M. (2006). Group therapy for abused and neglected youth: Therapeutic and child advocacy challenges. The Journal for Specialists in Group Work, 31, 311-326.

Wolfe, V. V. (2006). Child sexual abuse. In E. J. Mash \& R. A. Barkley (Eds.), Treatment of childhood disorders (pp. 647-727). New York: Guilford Press.

Zaidi, L. Y., \& Gutierrez-Kovner, V. M. (1995). Group treatment of sexually abused latency-age girls. Journal of Interpersonal Violence, 10, 215-227. 